\title{
Reptes de la comunicació especialitzada
}

\author{
Francesc Bernat \\ Departament de Filologia Catalana i Lingüística General, Universitat de \\ Barcelona
}

francesc.bernat@ub.edu

Intentar definir l'abast de la comunicació no és gens fàcil, entre moltes raons perquè en la societat humana tot, en el fons, és comunicació. És més, som humans perquè ens comuniquem, perquè allò que dona sentit a la nostra existència és l'intercanvi d'informació amb la resta de la nostra comunitat. Remarquem també aquest darrer mot: la comunitat és amb qui ens comuniquem més habitualment. Comunicar, comunitat, comú; el que es comparteix, amb qui es comparteix. Vet aquí una possible definició de les societats humanes.

Els nous articles que teniu a continuació són un reflex de les múltiples formes que pren la comunicació: des de la pragmàtica fins a la salut, passant per l'educació i el dret. No són totes les facetes que pot presentar (necessitaríem uns quants monogràfics), però sí que és una mostra significativa de recerques molt recents i un exemple de les múltiples mirades amb les quals es pot entendre la comunicació.

Obre el monogràfic un article sobre l'ambigüitat, un fenomen transversal a la comunicació. L. Payrató ens demostra que els dobles sentits estan molt relacionats amb els registres del llenguatge. Fins i tot, després d'analitzar la parla corrent, la llengua literària i els llenguatges d'especialitat, l'autor arriba a la conclusió que hi ha un grau i un tipus d'ambigüitat per a cada registre. Seguint amb els llenguatges especialitzats, A. Pou reflexiona en el segon article sobre una de les principals paradoxes de la comunicació en el món del dret: el fet que la cerca de la màxima objectivitat i precisió dugui els juristes a abusar de la impersonalització i la tecnificació, amb la qual cosa la comprensibilitat dels textos jurídics esdevé difícil i s'acreix la distància amb els ciutadans, justament el contrari del que es pretén. A continuació, el tercer article se centra en l'àmbit de la comunicació interna de les organitzacions. Y. Stefanu i M. Navia hi reflexionen a propòsit dels canvis que la pandèmia de la Covid ha impulsat en aquest camp. En aquest sentit, analitzen sobretot els pros i els contres de les videoconferències a partir d'un treball de camp realitzat en empreses espanyoles i colombianes.

Després d'aquest primer bloc, es troben dos articles dedicats a la relació entre comunicació i educació. Així, la contribució de D. Bueno i A. Forés és un excel-lent estat de la qüestió sobre la neuroeducació, un nou camp que se situa entre les ciències de l'educació i la neurociència. Si bé aquesta ciència interdisciplinària està començant a difondre unes propostes molt prometedores en l'educació, amb un nombre creixent d'aplicacions exitoses a les aules, els autors són conscients que es tracta d'un àmbit de recerca molt nou en què encara cal investigar molt. Seguidament, R. Estopà ens parla sobre una de les dificultats amb què es troben els nens en el procés d'aprenentatge del coneixement científic: la comprensió dels termes especialitzats usats a l'aula. Com a solució, l'autora proposa elaborar un diccionari de ciència escolar a partir de la metodologia del coneixement $i$ el desconeixement compartit, un projecte que l'IULA ja ha dut a la pràctica.

A continuació, trobarem tres articles sobre la comunicació en el món de la salut, tant d'actualitat darrerament. El primer, de S. Ramos, reflexiona sobre la comunicació 
mèdica a la societat durant la pandèmia de la Covid-19 i els reptes ètics que planteja aquesta experiència. Segons aquest autor, vam viure una autèntica allau d’informació (infodèmia) que no es va saber gestionar adequadament i va crear desconcert a la ciutadania, perquè no es van tenir prou en compte alguns principis ètics i deontològics fonamentals. Seguidament, A. Fernández i M. Consuegra fan una reflexió sobre un dels aspectes més problemàtics de la comunicació mèdica: com dir les males notícies als pacients i les seves famílies. Les autores arriben a la conclusió que cal dissenyar estratègies per millorar significativament aquesta comunicació a partir d'identificar i conèixer les dificultats, necessitats i preferències de tots els implicats, tant metges com pacients. Finalment, A. Kotátková ens parla dels casos clínics literaturitzats o contes clínics, un gènere a cavall entre la medicina i la literatura que va néixer en el món de la salut mental i que ha estat molt emprat per grans divulgadors científics. L'interès d'aquests relats rau en el fet que, malgrat allunyar-se dels casos clínics tradicionals, sempre pretenen els mateixos objectius: humanitzar la medicina, donar a conèixer algunes malalties i desestigmatitzar l'experiència de viure-les.

Finalment, M. Murillo clou el monogràfic amb un article sobre la comunicació alimentària, un camp que està agafant un protagonisme social creixent $\mathrm{i}$ que està cridat a tenir-ne encara més en el futur. En síntesi, l'autor adverteix que el món de l'alimentació s'està modificant profundament i que la societat no pot permetre's el luxe de tenir comunicadors que desconeguin la complexitat creixent del món alimentari.

Som conscients que molts camps de la comunicació han quedat fora d'aquest monogràfic, però estem segurs que hem aconseguit reflectir la complexitat d'aquest món. En definitiva, del món en què vivim, i que, precisament per això, anomenem «societat de la informació». 